\title{
Correction to: Development of a Sustainable Alternative for the Ammoniacal Cyanidation of Copper-Gold Ores Through a Biological Approach
}

\author{
Milad Allameh $^{1} \cdot$ Mohammad Raouf Hosseini $^{1}{ }^{10} \cdot$ Ebrahim Azimi $^{1}$
}

Published online: 6 January 2021

(c) The Minerals, Metals \& Materials Society 2021

\section{Correction to:}

Journal of Sustainable Metallurgy (2020) 6:796-808

https://doi.org/10.1007/s40831-020-00316-0

There are inaccuracies in the graphical abstract presented in this article.

Below is a corrected version of the graphical abstract.

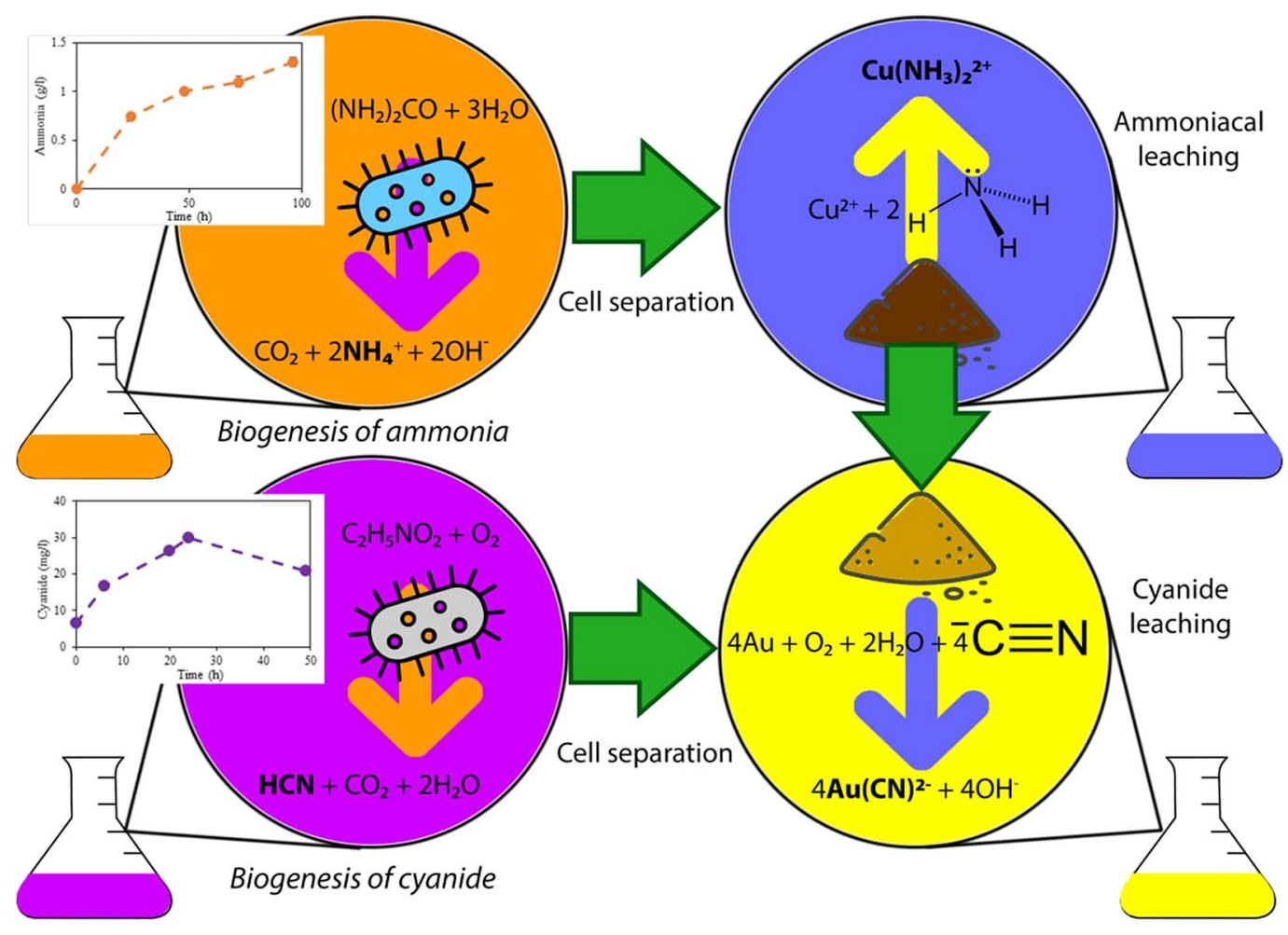

The original article can be found online at https://doi.org/10.1007/ s40831-020-00316-0.

Mohammad Raouf Hosseini

r.hosseini@iut.ac.ir

1 Department of Mining Engineering, Isfahan University of Technology, 8415683111 Isfahan, Iran
Publisher's Note Springer Nature remains neutral with regard to jurisdictional claims in published maps and institutional affiliations. 